\title{
The relevance of health state after treatment in prioritising between different patients
}

\author{
Erik Nord National Institute of Public Health, Oslo, Norway
}

\section{Author's abstract}

In $Q A L Y$-thinking, an activity that takes $N$ people from a bad state (including 'dying') to the state of healthy for $X$ years should have priority over an activity that takes $N$ other people from the same bad state to a state of moderate illness for the same number of years (given equal costs). An empirical study indicates that this view may not be shared by the general public in Norway. Subjects tended to emphasise equality in value of life and in entitlement to treatment rather than level of health after treatment. The relevance of costs per $Q A L Y$ in prioritising between different health care programmes in Norway is thereby brought in to doubt. While the sample in the study is too small to support firm policy conclusions, the results should contribute to an increased interest among health economists in actually measuring people's ethical preferences in matters of prioritising, rather than taking it for granted that their own values are shared by the general public.

\section{Introduction}

A common health economist point of view is that the priority of an activity should be determined by the quantity of well life - measured in QALYs produced by the activity per unit of cost (see for instance (1)). An implication of this view is that an activity that takes $\mathrm{N}$ people from a bad state (including 'dying') to the state of healthy for X years should have priority over an activity that takes $\mathrm{N}$ other people from the same bad state to a state of moderate illness for the same number of years.

Harris (2) has presented a critique of this position in the case of life-saving or prolongation of life. In Harris's own words:

'... we must think that each life is valuable. Each life counts for one and that is why more count for more' (3).

'If for example some people were given life-saving

\section{Key words}

QALY; cost-utility; prioritising; value of life; health programme evaluation; utility assessment. treatment in preference to others because they had a better quality of life than those others, ...., this would amount to regarding such people as more valuable than others on that account' (4).

'The state must ... treat each citizen with equal concern and respect' (4).

'Life-saving resources should simply be allocated in ways which do not violate the individual's entitlement to be treated as the equal of any other individual in the society' (4)

Essentially, the question is whether in the allocation of scarce resources lives in good health should be given higher priority than lives in less good health. The question is an ethical one. There is no scientific answer to it. As noted by Alan Williams in his comment on Harris's article: 'At the end of the day we simply have to stand up and be counted as to which set of principles we wish to have underpin the way the health care system works' (5).

Such counts are scarce. Support of Williams's view may, however, be found in a study by Patrick, Bush and Chen (6). Graduate students and health leaders in New York were asked to value - in terms of equivalence in numbers - saving the lives of people in different states of illness, in relation to saving the lives of healthy people. Priority was clearly given to the latter category. For instance, saving the life of a healthy person was considered approximately equivalent to saving the lives of two people with visual impairment and limited travelling and social activity and equivalent to saving the lives of three people sitting in a wheelchair unable to work.

Recently, a similar study was conducted at the National Institute of Public Health in Oslo. The results indicate that Harris's egalitarian views on the value of life may be very much in line with social preferences in Norway. The consequences for the relevance of QALYs in health programme evaluation in Norway are potentially quite serious.

The sample is too small and the selection of people too special to support broad generalisations. However, it was suggested earlier that 'much of 
the reason why policy has in the past failed to adopt the recommendations of economists is ... . because analysts have failed to integrate into their analysis some of the real constraints faced by decision-makers' (7). The present study supports this view and should contribute to increased interest among health economists in measuring people's ethical preferences in matters of prioritising, rather than taking it for granted that their own values are shared by the general public. In this connection, the questionnaires used in this study may, it is hoped, be useful to other researchers.

Two limitations to the study should be noted at the outset:

Firstly, the study focuses on the significance of the resulting health state for prioritising. In his article, Harris also criticised the idea of prioritising on the basis of gained life years rather than gained lives. This is not the issue here. However, questionnaires similar to the ones used in this study could be used in future studies to see whether the general public shares Harris's view in this respect.

Secondly, the study focuses on prioritising between different people. The relevance of the resulting health state in deciding between different treatment alternatives for individual patients is not questioned by this study.

\section{Methods}

It is commonly recognised that ethical considerations of health personnel in clinical situations may differ from those of administrators and politicians when making budget decisions concerning statistical patients. In the study, the issue of prioritising was addressed within both these contexts by means of two different questionnaires (see appendix).

In the first questionnaire, subjects were asked how they felt a hospital should prioritise between two patients admitted to the hospital within a few hours of each other. Both were described as being in a life-threatening condition. One could regain full health if treated, the other could be given a life with moderate pain and dependency on crutches for walking. The hospital might not manage to operate on both in time. In the subject's opinion, how should the hospital prioritise between the two? The subjects were asked to give a brief reason for their answer.

Initially, 'drawing lots' was offered as a response category to those who wished to give the two patients equal priority. However, a pilot study revealed that some subjects considered it irresponsible to draw lots and therefore found it impossible to express their indifference between the two patients. For this reason, the neutral category was changed to: 'They should be operated on in the order in which they were admitted to the hospital.'
The questionnaire was handed out to a hundred people working at the National Institute of Public Health in Oslo. These included researchers, engineers, laboratory personnel and secretaries. There were no manual workers in the sample. Sixtyone questionnaires were completed and returned.

In the second questionnaire, subjects were first asked how they as members of Parliament would prioritise between two proposed equally costly special units A and B. Unit A would save ten people per year from dying and give them full health. Unit $B$ would also save people from dying, but they would then live a life with moderate pain and dependency on crutches for walking. The question put to the subjects was: How many patients must be treated per year in unit B in order that you would find it just as valuable to spend the money on unit $B$ as on unit A?

The second questionnaire also contained a second question, identical to the first, except that the issue was now helping chronically ill people sitting in a wheelchair with strong pain, rather than saving people from dying.

The second questionnaire was mailed to 28 of the respondents to the first questionnaire who had expressed willingness to participate further. Twentyfive questionnaires were completed and returned. In 23 of these cases, statement of the respondent's name made it possible to link the response to the response given in the first questionnaire.

Immediately on return of the second questionnaire, the subjects were contacted on the telephone and asked how they had reasoned when giving their answers.

\section{Results}

The initial sample had a reasonably wide agedistribution (table 1). There is a strong overweight of women and of people with education at the college/university level.

In the decision situation at the hospital level, 48 subjects ( 79 per cent) felt that the two patients should be treated in the order in which they were admitted to the hospital (table 2). Only 9 subjects (15 per cent) were in favour of giving priority to the patient with the better expected outcome.

In commenting on their responses, 31 subjects in the majority group of 48 explicitly argued in terms of equality in value of life and/or entitlement to treatment (not indicated in table). Most of the remaining 17 did not give any clear reason for their answer. In the group of 9 subjects who gave priority to Mrs Anderson, 6 subjects explicitly stated better outcome as the reason. The remaining 3 subjects did not give any reason.

There were no significant differences between men and women in their responses to the first questionnaire (table 3 ). In women, all those with only primary or secondary school were in favour of 
treating in order of admission, while only 18 out of 26 in the college/university group, ie 69 per cent, took this position. Six subjects in the latter subgroup, ie 23 per cent, gave priority to the patient with the better outcome. The difference between the two educational subgroups was statistically significant at the 10 per cent level.

The male subgroup was too small and the educational variance too little to permit this kind of comparison.

In table 4, responses to the second questionnaire are presented by respondent category in the first questionnaire. There is a very marked pattern. Those who disregarded difference in outcome when choosing between two patients at the hospital level also attached little weight to such difference in the budget-decision exercise. This is true also when the issue is helping the chronically ill rather than saving people from dying. On the other hand, those few who did attach weight to difference in outcome in the hospital-level exercise, tended to do so in the budget-decision context as well.

In the subsequent telephone interview, 15 out of 18 subjects who gave 10 or 11 as equivalence numbers in the case of life-saving explicitly and spontaneously pointed to equality in value of life and/or equality in entitlement to treatment. Three subjects said that what mattered was the number of people that could be helped, not the outcome in terms of quality of life. The reasons given for the equivalence numbers concerning the chronically ill were very much the same.

\section{Discussion}

The questions in this study were carefully designed to make the subjects perceive the patients or patient groups in each question as identical in all respects except for health state after treatment. In particular, we did not want the subjects to assume that the patients with the less favourable outcome would be more costly to society in the long run. The subjects' explanations of their own answers indicate that this goal was largely achieved. Only in two out of sixtyone cases did the explanations reveal that the subject had attached weight to a difference other than difference in outcome.

When considering the responses to the equivalence-in-numbers questions, there is a problem of indivisibility that must be taken into account. Those who answered ' 11 ' did not mean there was 'a ten per cent difference' in the value of the two health improvements being compared. According to the explanations given in the telephone interviews, these subjects simply chose the lowest possible number above 10. The overriding consideration for these subjects is the number of patients that can be helped. Only if the numbers are equal (10 versus 10 ) would they give priority to the alternative with the better outcome in terms of quality of life.
The sample in this study was a special one in terms of subjects' education and occupation. Also, only 61 per cent of those asked responded to the first questionnaire, and only 38 per cent of these responded to the second. We do not know what characterises the non-responders. Altogether our data need not be representative of views in the Norwegian population at large.

Still, the results are quite striking. Also, the sample has a strong overweight of people with high education, and these seem to be more inclined to prioritise according to expected health outcome than the less educated. In a random national sample the percentage of respondents wishing not to attach weight to differences in health outcome may therefore very well turn out to be even higher than in this study.

What seems to count for the vast majority of the subjects, is the view that individuals are equally valuable and equally entitled to treatment. These views were not in any way suggested to the subjects, but expressed freely by them in response to open questions. They are precisely the views that Harris (2) has expressed earlier (see introduction).

The results are contrary to those obtained earlier in a sample of American residents ((6), see introduction). This is not surprising. As noted by Culyer (7), 'the inheritances of the past and differences in cultural conditioning may affect preferred choices'. Unlike the US, Norway has a national health service with very limited out-of-pocket payment. The very reason for this is Norwegians' strong adherence in general to the principle of equal entitlement to treatment. It would therefore not be surprising if the results obtained in the present convenience sample were reproduced in a random population sample in Norway. And while Culyer is certainly right in pointing out that 'none of us should suppose that what we hypothesise to be best for our own health care system is going to be best for anyone else', it would not be surprising if similar results were obtained in other European countries with a strong national health service.

In his article, Harris was concerned with the value of life-saving. The responses to the third question in this study indicate that equality in value of life and entitlement to treatment may be considered relevant by many also where health improvement rather than live-saving is concerned.

Equality in value of life is not necessarily a view that applies in all circumstances. Earlier studies have suggested that the public in England and Sweden regard lives of young people and people with small children as more valuable than other lives $(8,9)$. The present study is not incompatible with such views. It merely indicates that health state after treatment does not seem to be a criterion on which Norwegian subjects would place strong emphasis. Whether they would take account of age and family situation is an issue for future research. 
Table 1

Characteristics of the initial respondents $(\mathbf{N}=61)$

Sex

$\begin{array}{lr}\text { Men } & 19 \\ \text { Women } & 38 \\ \text { Missing } & 4\end{array}$

Age

Education

$\begin{array}{lr}20-29 & 8 \\ 30-39 & 18 \\ 40-49 & 14 \\ 50-59 & 8 \\ 60-69 & 9 \\ \text { Missing } & 4\end{array}$

Primary 3

Secondary $\quad 10$

College/University $\quad 45$

Missing
Table 2

Prioritising at hospital level.

Mrs Anderson should be operated on first:

Number $\quad \%$

$9 \quad 14.8$

Mrs Peterson should be operated on first:

2

They should be operated on in order in which they were admitted to the hospital:

Uncertain:

2

Total:

Table 3

Distribution of responses to question at hospital level by sex and education Men Women

\begin{tabular}{ccc}
\hline All & Primary/ & College/ \\
Secondary & University
\end{tabular}

Anderson first:

3

6

6

Uncertain:

0

2

0

Admission order:

14

30

12

18

Peterson first:

2

0

0

0

All:

19

38

12

26

Table 4

Distribution of responses with respect to equivalence numbers at budget level by respondent category in question at hospital level.

Equivalence
number
10
11
15
20
30
50
100
All

\begin{tabular}{|c|c|}
\hline \multicolumn{2}{|c|}{ Life-saving } \\
\hline Anderson & $\begin{array}{l}\text { Equal } \\
\text { priority }\end{array}$ \\
\hline 1 & $\begin{array}{r}11 \\
7 \\
1\end{array}$ \\
\hline 1 & \\
\hline 1 & \\
\hline 1 & \\
\hline 4 & 19 \\
\hline
\end{tabular}

\begin{tabular}{cc}
\multicolumn{2}{c}{ Chronically ill } \\
\hline Anderson & $\begin{array}{c}\text { Equal } \\
\text { priority } \\
\\
\end{array}$ \\
9 \\
6 \\
2 & 1 \\
1 & 1 \\
1 & 1 \\
4 & \\
&
\end{tabular}


In all three questions in this study, the subjects were asked to compare the outcome 'healthy' with an outcome consisting in a moderate state of illness (moderate pain, dependency on crutches for walking). The subjects' explanations show that this state was perceived as significantly better than the initial state and as a state in which people may very well live a dignified life. For very severe outcome states, or for states that are only marginally better than the initial state, the responses might have been different. In other words, the data do not imply that the respondents consider the variable 'resulting health state' as completely irrelevant in prioritising between patients. But the data do suggest that this variable may have limited relevance as a criterion for society in allocating scarce resources among patients. The possible negative implications for the use of costs per QALY as a criterion for prioritising among different health care programmes are obvious.

The sample in this study is too small and the selection of people too special to support firm conclusions and broad generalisations. However, the results should contribute to an increased interest among health economists in actually measuring people's ethical preferences in matters of prioritising, rather than taking it for granted that their own values are shared by the general public. In this connection, it is hoped the questionnaires (see appendix) will be useful to other researchers.

Erik Nord, MSc, PhD, is a Research Scientist at the National Institute of Public Health, Oslo, Norway

\section{Appendix}

FIRST QUESTIONNAIRE

Mrs Anderson and Mrs Peterson are 60-year-old housewives. Each of them has contracted a lifethreatening disease. A major operation can make Mrs Anderson completely healthy. An equally major operation can give Mrs Peterson a life with moderate pain and dependency on crutches for walking. There is no question of further treatment or later medication. Both know the expected outcome of the operation, and both wish to be treated.

They have been admitted to the same hospital within a few hours of each other. It is uncertain whether the hospital will manage to operate on both in time. In your opinion, how should the hospital prioritise between the two? Please read the task once more and think a moment before ticking one of the boxes below!

Mrs Anderson should be operated on first. Mrs Peterson should be operated on first. They should be operated on in the order in which they were admitted to the hospital.

Reason for answer:

\section{SECOND QUESTIONNAIRE}

Question 1:

Imagine yourself as a member of the subcommittee for health affairs in Parliament. The committee is discussing next year's budget proposal for the National Hospital. There is agreement in the committee, except for on one issue, where there are two competing proposals.

The first proposal is to establish a special unit A for treatment of a rare and very severe disease. The unit exists only in a few hospitals in the world. These hospitals do not have the capacity to receive Norwegian patients. Today, such Norwegian patients are therefore without any possibility of treatment and die within weeks of the onset of the disease. With the proposed unit at the National Hospital all such patients could have an operation that would make them completely well.

The other proposal is to establish a special unit B for a different group of patients for whom there is no possibility of treatment in Norway today and no available treatment capacity abroad. These too die within weeks of the onset of the disease. With the proposed special unit B all such patients could have an operation that would give them a life with moderate pain and dependency on crutches for walking. There would be no question of further treatment or medication.

In both cases the disease occurs in women at the age of 65-70 years, ie mostly non-working persons.

The two units cost the same. Only one of them will receive funding in this budget.

Special unit $A$ is expected to treat 10 patients per year. How big must the expected number of patients per year be in unit $B$ in order that you personally would find it just as valuable to spend the money on unit $B$ as on unit $A$ ?

We would like you to think a little before answering!

Answer: (approximate number of persons).

\section{Question 2:}

As question 1, except that the words '. . . die within weeks after the onset of the disease' were replaced by '... must sit in a wheelchair and endure strong pain'.

\section{References}

(1) Williams A. Who is to live? A question for the economist or the doctor? World hospitals 1987; 23: 34-36.

(2) Harris J. QALYfying the value of life. Fournal of medical ethics 1987; 13: 117-123.

(3) See reference (2): 120.

(4) See reference (2): 121.

(5) Williams A. Response: QALYfying the value of life. Fournal of medical ethics 1987; 13: 123.

(6) Patrick D L, Bush J W, Chen M M. Methods for measuring levels of well-being for a health status index. Health services research 1973; 8: 228-245. 
(7) Culyer A J. Demand-side socialism and health care. Paper to the Second World Congress on Health Economics, Zurich: 1990.

(8) Charny M C, Lewis P A, Farrow S C. Choosing who shall not be treated in the NHS. Social science and medicine 1989; 28: 1331-1338.

(9) Bråkenhielm C R. Vård på lika vilkår (Health care on equal terms). In: Caltorp J, Bråkenhielm $\mathrm{C} \mathrm{R}$, eds. Vardens pris (The price of care). Stockholm: Verbum forlag, 1990. 